\title{
Techniques for Determining the Treatment Costs of Cervical Cancer: A Systematic Review
}

\author{
Candice Amorim de Araújo Lima Santos ${ }^{1}$, Ariani Impieri Souza ${ }^{1,2 *}$, Suely Arruda Vidal ${ }^{1}$ \\ ${ }^{1}$ Instituto de Medicina Integral Professor Fernando Figueira-IMIP, Recife, Brazil \\ ${ }^{2}$ Faculdade Pernambucana de Saúde-FPS, Recife, Brazil \\ Email: *ariani.impieri@gmail.com
}

How to cite this paper: de Araújo Lima Santos, C.A., Souza, A.I. and Vidal, S.A. (2019) Techniques for Determining the Treatment Costs of Cervical Cancer: A Systematic Review. Open Journal of Obstetrics and Gynecology, 9, 117-128.

https://doi.org/10.4236/ojog.2019.92012

Received: January 7, 2019

Accepted: January 30, 2019

Published: February 2, 2019

Copyright (c) 2019 by author(s) and Scientific Research Publishing Inc. This work is licensed under the Creative Commons Attribution International License (CC BY 4.0).

http://creativecommons.org/licenses/by/4.0/

\begin{abstract}
Background: Uterine cervical cancer (UCC) represents a public health problem in many part of the world. The use of new technologies is leading to increased treatment costs, resulting in a substantial economic impact worldwide. Standardization of economic evaluation methods is needed to improve comparisons between jurisdictions. Objective: To identify the methods used to measure the cost of treating invasive UCC, and to search for correlations between cancer treatment expenditures and local economies. Methods: We searched articles in MEDLINE, LILACS, and SciELO with no language restrictions, and included publications from January 01, 2007 to December 31, 2016. Studies were included if they described the annual direct cost of invasive cervical cancer and detailed the costing method. Complete economic evaluations were excluded. Results were described in 2016 international dollars. Results: Of 1581 studies initially reviewed, 13 articles were included in the analysis. Six articles used a bottom-up; six used a top-down approach and one used both. Annual cost per patient varied from I\$ 2146.22 (Poland) to $34,351.54$ (Sweden). Middle-income countries (MIC) spent median $72.52 \%$ of its GDP per capita on the treatment of invasive cervical cancer, while high-income countries (HIC) spent median $30.12 \%(\mathrm{p}=0.032)$. No significant difference was found when separated by costing method. Conclusions: We found that, for the treatment costs of invasive UCC, the percentages of GDP per capita were statistically higher in MIC than in HIC. However, no significant difference was found between costing methods, and the top-down approach could be used.
\end{abstract}

\section{Keywords}

Cervical Cancer, Costs and Cost Analysis, Costing Method, Systematic Review 


\section{Introduction}

Uterine cervical cancer (UCC) is the fourth most common malignant neoplasia in women worldwide [1]. It has a heterogeneous distribution, with $84 \%$ of cases occurring in less developed regions [2]. Cancer treatment costs are increasing as a result of new medications, innovative surgical procedures, radiotherapy, and technologies related to diagnosis and treatment, thereby resulting in a substantial economic impact for those who pay for healthcare in most countries. The estimated 14 million new cases of cancer annually worldwide lead to significant economic costs, and the total annual economic cost of cancer in 2010 was estimated at approximately US $\$ 1.16$ trillion. Although impressively high, this figure is underestimated and not equally distributed across all nations [3]. Even though low and middle-income countries represent $84.5 \%$ of the world population and $61.3 \%$ of new cancer cases globally, these areas account for only $6.2 \%$ of financial expenditures on cancer [4]. Middle-income countries (MICs) are defined as having a per capita gross national income (GNI) of US\$1026 to $\$ 12,475$ (2011) [5].

Since resources are limited, economic evaluation has emerged as an important tool in evaluating healthcare [6]. Complete or full economic evaluation refers to the costs and consequences associated with some medical conditions. Studies that do not consider the consequences and contain only cost descriptions represent partial economic evaluations. These studies are defined as cost analysis, cost descriptions, cost of illness, or burden of illness, and can be conducted using different costing methods [7].

Costs refer to all expenditures related to an intervention, including the treatment itself, adverse effects, and acute or late complications [8]. These costs may be direct or indirect. Direct costs are related to spending on medical (physician time, tests, and drugs) and non-medical treatment (food, transport, accommodation, and home aides). Indirect costs refer to lost productivity resulting from absence from work or loss of life due to disease or treatment [9].

The cost of an intervention can be estimated by means of a top-down (TD) or a bottom-up (BU) method. In a TD approach, an adequate population is identified and their aggregated economic or resource costs of a particular health intervention are extracted from the health services billing data. It is then adjusted by cost to charge ratios. In a BU method, estimates are obtained in a two-step process. First, the utilization frequency of individual resources is obtained, after which the frequencies are multiplied by each unit's cost and summed to yield a total cost. A full assessment of the costs is described by some as micro costing, where details of additional costs are provided-such as the contribution of the care provided by health workers, supplies, or ancillary services [9]. However, this nomenclature is unclear, and some authors use BU as a synonym of micro costing and TD as a synonym of macro costing or gross costing [10] [11]. In addition, there are controversies about the ideal costing method. When different costing methods are used, different cost estimates are frequently reached [9]. 
Conducting cost description studies may be a difficult task, mainly for low and middle-income countries. Another major point of discussion is transferability of health economic data between jurisdictions; the results of cost evaluations may vary from place to place because of differences in the severity of the disease, the availability of health care resources, clinical practice patterns, and prices [12].

All over the world, especially in developing countries, strong economic health policies are necessary and economic evaluation studies are essential in order to identify the best action for each situation. Thus, the aim of this review is to identify the methods used to measure the cost of treating invasive UCC, and to search for correlations between cancer treatment expenditures and local economies, in articles published in the last ten years.

\section{Methods}

This systematic review incorporated studies where costing methods of invasive UCC treatment costs were described.

Studies were identified by searching MEDLINE, LILACS, and SciELO from January 01, 2007 to December 31, 2016. The search strategy included the descriptors: "uterine cervical neoplasms" or "cervical cancer" were combined with: "costs and cost analysis", "drug costs", "cost of illness", "cost-benefit analysis", "economics", "direct service costs" and "hospital costs". A free search was also conducted in the references of studies considered relevant. No language restriction was applied.

Studies were included if they met the following criteria: 1) was primary research; 2) described the annual direct cost of invasive UCC; and 3) described a detailed costing method. An initial selection of titles and abstracts was conducted by two independent researchers. Discordant cases were evaluated at a consensus meeting. Thereafter, articles were read in full to ensure that they met the inclusion criteria. Complete economic evaluations, which comprised "cost-effectiveness, cost-benefit, and cost-utility analysis", were excluded.

Data were collected using a spreadsheet that contained information about the author, location, year of publication, costing method, total annual cost, and annual cost per patient. For comparison, we searched economic and demographic data referent to each country discussed in this analysis. Based on their GNI, countries were divided into MIC (between US\$1026 and US\$12,475) and high-income countries (HIC) (more than US\$12,476) [5].

All costs were inflated for 2016 and then converted to 2016 International dollar (I\$) using purchasing power parities (PPP) from the World Bank consumer prices (Table 1) [13] [14].

In order to test the differences in costs between MIC and HIC, statistical analysis was done using a non-parametric Kruskal-Wallis test in STATA, version 12.1 SE. A p value < 0.05 was considered statistically significant.

This project was approved by the Ethics Committee at IMIP (document 
Table 1. Annual inflation rate between 2006 and 2016.

\begin{tabular}{cccccccccccccc}
\hline & \multicolumn{10}{c}{ Inflation rate per year (\%) } \\
\cline { 2 - 10 } Country & 2006 & 2007 & 2008 & 2009 & 2010 & 2011 & 2012 & 2013 & 2014 & 2015 & 2016 \\
\hline Belgium & 4.487 & 5.345 & 8.95 & 3.044 & 3.513 & 5.000 & 3.852 & 2.784 & 2.762 & 1.595 & 1.614 \\
Brazil & 4.184 & 3.637 & 5.663 & 4.886 & 5.038 & 6.636 & 5.402 & 6.202 & 6.332 & 9.028 & 8.739 \\
Canada & 2.002 & 2.138 & 2.370 & 0.299 & 1.777 & 2.912 & 1.516 & 0.938 & 1.907 & 1.125 & 1.429 \\
Italy & 2.070 & 1.821 & 3.375 & 0.750 & 1.540 & 2.741 & 3.041 & 1.220 & 0.241 & 0.039 & -0.100 \\
Japan & 0.249 & 0.060 & 1.380 & -1.353 & -0.720 & -0.268 & -0.052 & 0.346 & 2.762 & 0.790 & -0.117 \\
Mexico & 3.629 & 3.967 & 5.125 & 5.297 & 4.157 & 3.407 & 4.112 & 3.806 & 4.019 & 2.721 & 2.821 \\
Morocco & 3.285 & 2.042 & 3.707 & 0.995 & 0.987 & 0.922 & 1.279 & 1.888 & 0.435 & 1.558 & 1.635 \\
Poland & 1.115 & 2.388 & 4.349 & 3.826 & 2.707 & 4.258 & 3.557 & 1.034 & 0.107 & -0.991 & -0.610 \\
Sweden & 1.360 & 2.212 & 3.437 & -0.494 & 1.158 & 2.961 & 0.888 & -0.044 & -0.18 & -0.047 & 0.984 \\
Tunisia & 4.491 & 3.417 & 4.921 & 3.525 & 4.416 & 3.544 & 5.138 & 5.799 & 4.938 & 4.857 & 3.711 \\
USA & 3.226 & 2.853 & 3.839 & -0.356 & 1.640 & 3.157 & 2.069 & 1.465 & 1.622 & 0.119 & 1.262 \\
\hline
\end{tabular}

*Source: The World Bank, 2017 [15].

number 4026-14). As secondary published data were analyzed, no informed consent was needed.

The selection algorithm is described in Figure 1.

\section{Results}

The initial search retrieved 1581 references. Among these, 1546 articles were excluded by title and another 22 were excluded because of eligibility criteria. The remaining 13 articles were included in the analysis.

The economic characteristics of the countries referred to in this review are outlined in Table 2.

Ten studies used the payer perspective and included only direct costs. Four studies used the societal perspective, where direct and indirect costs were calculated. For these articles, indirect costs represented between 14.11\% (only morbidity costs) and $80.50 \%$ (morbidity and mortality costs included) of the total costs. Nine studies did not name the costing method, although they detailed how costs were derived. In this review, the costing method (CM) of each article was classified into TD and BU; these methodologies were used in seven articles each, with one article using both (see Table 3). Only four studies specified that the cost referred to the first year of diagnosis [20] [21] [22] [23].

The annual per patient invasive UCC treatment cost, considering only direct costs, were inflated to the 2016 local currency and then converted to International dollar (I\$). Results varied from I\$2146.22 (Poland) to 34351.54 (Sweden), mean of I $\$ 16390.15$ ( \pm 9566.20$)$. For comparison, we obtained the ratio between gross domestic product (GDP) per capita (in 2016 I\$) and the annual cost per 


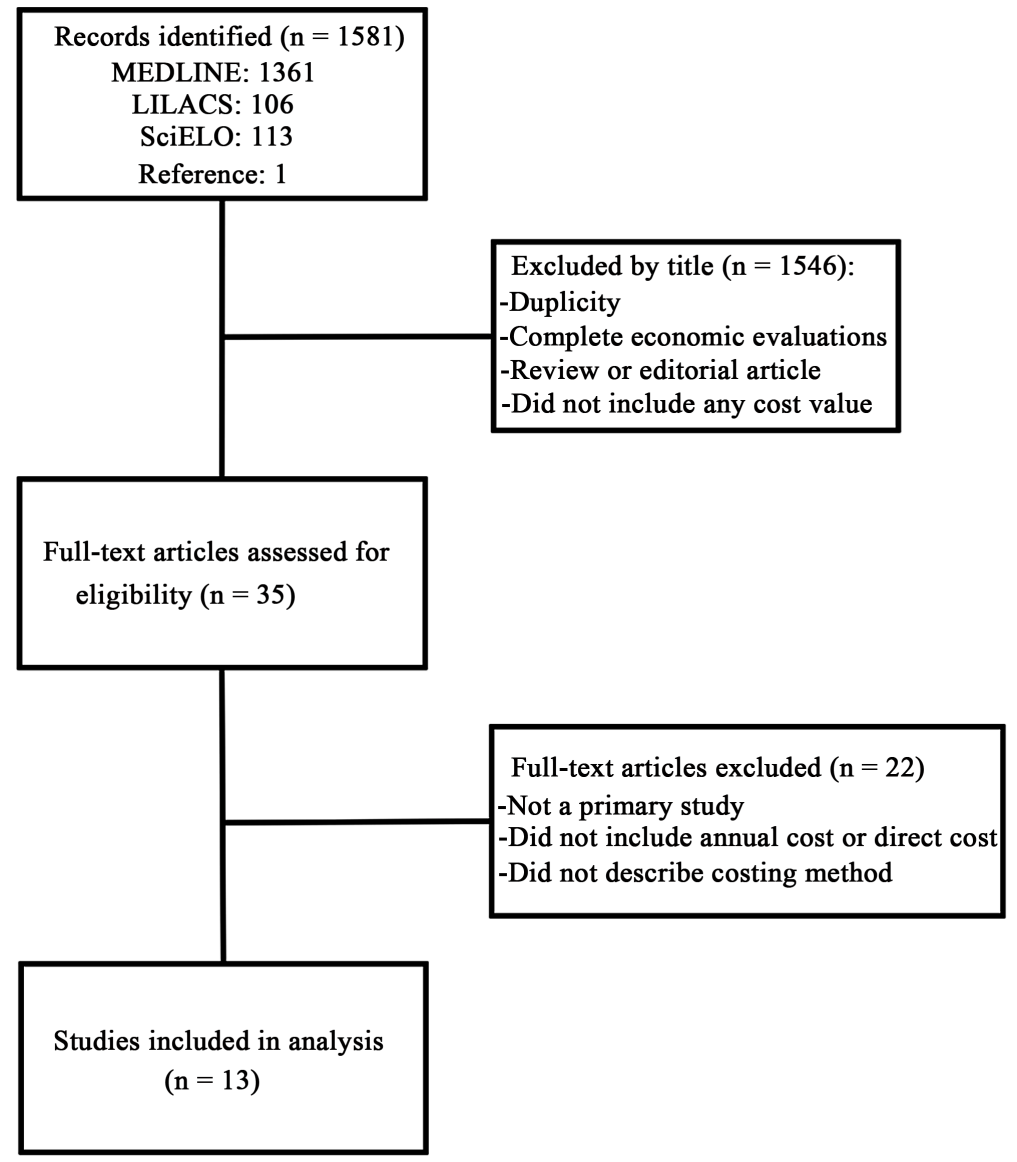

Figure 1. Literature selection process.

Table 2. Economic characteristics by country.

\begin{tabular}{ccccccc}
\hline Local & $\begin{array}{c}\text { GDP (2016) } \\
\text { (USD million) } \\
{[16]}\end{array}$ & $\begin{array}{c}\text { GDP (2016) } \\
\text { per capita } \\
\text { USD [17] }\end{array}$ & $\begin{array}{c}\text { GDP (2016) } \\
\text { per capita } \\
\text { I\$ }[18]\end{array}$ & $\begin{array}{c}\text { GNI per capita in } \\
\text { USD (2011) [19] }\end{array}$ & $\begin{array}{c}\text { Local } \\
\text { currency }\end{array}$ & $\begin{array}{c}\text { PPP } \\
(2016) \\
{[13]}\end{array}$ \\
\hline Belgium & 466365.73 & 41096.20 & 46383.20 & 47070.00 & EUR & 0.80 \\
Tunisia & 42062.55 & 3688.6 & 11598.50 & 3690.00 & TND & 0.68 \\
Morocco & 101445.00 & 2832.40 & 7837.90 & 3000.00 & MAD & 3.54 \\
Brazil & 1796186.59 & 8649.90 & 15127.80 & 11010.00 & BRL & 1.99 \\
Japan & 4939383.91 & 38894.50 & 41469.90 & 46880.00 & JPY & 102.04 \\
Canada & 1529760.49 & 42157.90 & 44025.20 & 47060.00 & CND & 1.27 \\
Sweden & 510999.80 & 51599.90 & 49174.90 & 55660.00 & SEK & 8.98 \\
Italy & 1849970.46 & 30527.30 & 38160.70 & 37680.00 & EUR & 0.72 \\
USA & 18569100.00 & 57466.80 & 57466.80 & 50460.00 & USD & 1 \\
Poland & 469508.68 & 12372.40 & 27810.50 & 12900.00 & PLN & 1.75 \\
Mexico & 1045998.07 & 8201.30 & 17861.60 & 9170.00 & MXN & 8.57 \\
\hline
\end{tabular}

GDP: Gross Domestic Product; GNI: Gross National Income; PPP: Purchasing Power Parity; USD: United States Dollar (US\$); I\$: International Dollar; EUR: Euro (€); TND: Tunisian dinar; MAD: Moroccan dirham; BRL: Real (R\$); JPY: Yen (¥); CND: Canadian Dollar; SEK: Swedish Krona; PLN: Zloty; MXN: Mexican Peso. 
Table 3. Study characteristics.

\begin{tabular}{|c|c|c|c|c|c|c|}
\hline Author & Location/Year & Perspective & CM by author & $\begin{array}{l}\mathrm{CM} \text { by } \\
\text { reviewer }\end{array}$ & Annual cost total & $\begin{array}{l}\text { Indirect and total } \\
\text { costs rate }(\%)\end{array}$ \\
\hline Annemans et al. [24] & Belgium/2008 & $\begin{array}{l}\text { Payer \& } \\
\text { Societal }\end{array}$ & NN & TD & $\begin{array}{c}8.4 \text { million }-12.3 \text { million } \\
\quad \text { (total costs) } \\
\quad 6.5 \text { million } \\
\text { (5.8 million }-7.9 \text { million) } \\
\text { (direct costs) (EUR) }\end{array}$ & 33.82 \\
\hline $\begin{array}{l}\text { Ben Gobrane } \\
\text { et al. [25] }\end{array}$ & Tunisia/2009 & Payer & NN & $\mathrm{BU}$ & 486847.00 (EUR) & NA \\
\hline Berraho et al. [20] & Morocco/2012 & Payer & $\mathrm{NN}$ & $\mathrm{BU}$ & 13589360.00 (USD) & NA \\
\hline Cheikh et al. [21] & Morocco/2016 & Payer & Micro-costing & $\mathrm{BU} \& \mathrm{TD}$ & 1429673.00 (USD) & NA \\
\hline Fonseca et al. [26] & $\begin{array}{c}\text { Roraima } \\
(\text { Brazil)/2010 }\end{array}$ & Payer & NN & $\mathrm{BU}$ & 609782.00 (BRL) & NA \\
\hline Hayata et al. [27] & Japan/2015 & Societal & Cost of illness & $\mathrm{TD}$ & $\begin{array}{c}159000000000.00 \text { (total costs) } \\
31000000000.00 \text { (direct costs) (JPY) }\end{array}$ & 80.50 \\
\hline Liu et al. [28] & $\begin{array}{c}\text { Ontario } \\
(\text { Canada }) / 2016\end{array}$ & Payer & Cost of illness & $\mathrm{BU}$ & $62888000.00(\mathrm{CND})^{\#}$ & NA \\
\hline Novaes et al. [29] & Brazil/2015 & Societal & Gross-costing & $\mathrm{TD}$ & $\begin{array}{c}82768409.00 \text { (total costs) } \\
71086509.00 \text { (direct costs) (USD) }\end{array}$ & 14.11 \\
\hline Östensson et al. [30] & Sweden/2015 & Societal & NN & $\mathrm{TD}$ & $\begin{array}{c}15830004.00 \text { (total costs) } \\
12220541.00 \text { (direct costs) (EUR) }\end{array}$ & 22.80 \\
\hline Ricciardi et al. [22] & Italy/2009 & Payer & $\mathrm{NN}$ & $\mathrm{BU}$ & 19210075.00 (EUR) & NA \\
\hline Insinga et al. [23] & USA/2008 & Payer & $\mathrm{NN}$ & $\mathrm{TD}$ & 129038950.00 (USD) $^{\#}$ & NA \\
\hline Holecki et al. [31] & Poland/2015 & Payer & NN & TD & 8766547.00 (PLN) & NA \\
\hline $\begin{array}{l}\text { Sanchez-Roman } \\
\text { et al. [32] }\end{array}$ & Mexico/2012 & Payer & NN & $\mathrm{BU}$ & $5190800.00(\mathrm{MXN})$ & NA \\
\hline
\end{tabular}

CM: Costing Method; NN: Not Named; TD: Top-Down; EUR: Euro; BU: Bottom-Up; NA: Not Applicable; USD: United States Dollars; JPY: Yen; CND: Canadian Dollar; PLN: Zloty; MXN: Mexican Peso. "Not described in the article, value calculated by this reviewer based on data in the article.

patient, results ranged from $7.71 \%$ to $241.63 \%$ (median $61.36 \%$ ). Final costs are outlined in Table 4.

Based on 2011 per capita GNI, Tunisia, Morocco, Brazil, and Mexico are defined as MIC by the World Bank [5]. The Kruskal-Wallis test revealed that MIC spent proportionally more than HIC $(\mathrm{p}=0.032)$, as illustrated in Figure 2.

However, when separated by costing method, no difference was found ( $\mathrm{p}=$ 0.522) (Figure 3).

\section{Discussion}

This review compared results by relating the adjusted cost of invasive UCC in 2016 I\$ in different countries with each country's GDP per capita, thus accommodating for the huge economic differences across jurisdictions.

Most studies used the payer perspective, where only direct costs were included. Indirect costs were described when the societal perspective was used. 


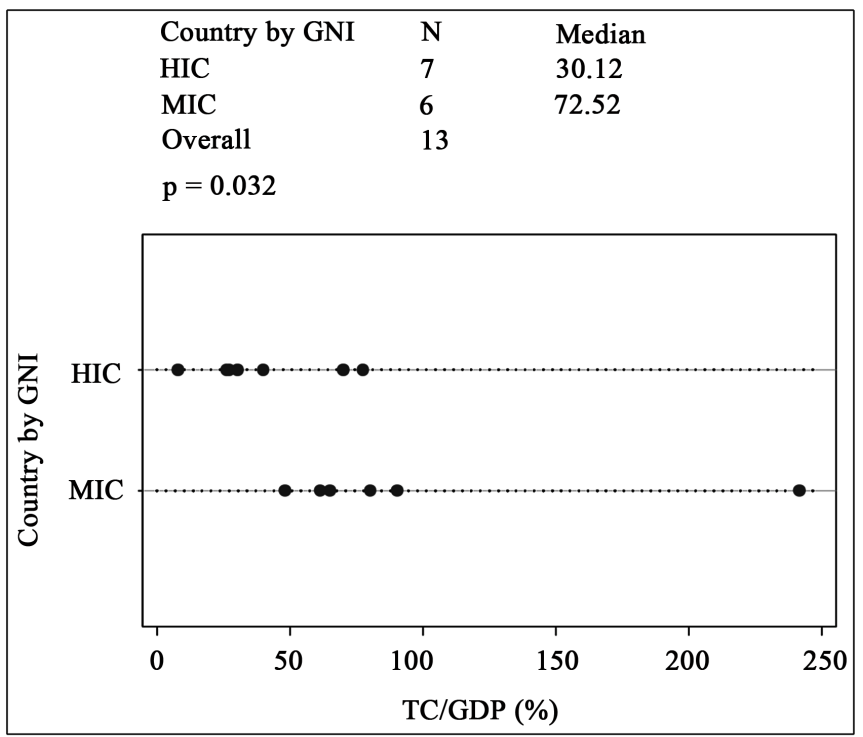

Figure 2. Costs percentage distribution according to gross national income. GNI: gross national income; HIC: high income countries; MIC: middle income countries; TC: total ICC treatment costs per patient per year; GDP: gross domestic product per patient.

Table 4. Uterine cervical cancer: annual cost per patient treatment in 2016 I\$ and percentage ratio between per capita gross domestic product and treatment cost.

\begin{tabular}{|c|c|c|c|c|c|}
\hline Local/Year & $\begin{array}{l}\text { Annual cost per } \\
\text { patient extracted } \\
\text { in the article }\end{array}$ & $\begin{array}{l}\text { Annual cost per } \\
\text { patient in local } \\
\text { currency inflated } \\
\text { to } 2016\end{array}$ & $\begin{array}{l}\text { GDP per } \\
\text { capita I\$ } \\
2016[19]\end{array}$ & $\begin{array}{c}\text { Annual cost } \\
\text { per patient in } \\
2016 \text { I\$ }\end{array}$ & $\begin{array}{c}\text { ICC } \\
\text { treatment } \\
\text { cost and } \\
\text { GDP rate }(\%)\end{array}$ \\
\hline Belgium/2008 & 9716.00 (EUR) & 14777.35 (EUR) & 46383.20 & 18471.69 & 39.82 \\
\hline Tunisia/2009 & 1766.00 (EUR) & 5120.71 (TND) & 11598.50 & 7530.45 & 64.93 \\
\hline Morocco/2012 & $6899.91(\mathrm{EUR})^{*}$ & 67043.51 (MAD) & 7837.90 & 18938.84 & 241.63 \\
\hline Morocco/2016 & 2599.00 (USD) & 25022.68 (MAD) & 7837.90 & 7068.55 & 90.18 \\
\hline $\begin{array}{c}\text { Roraima } \\
(\text { Brazil)/2010 }\end{array}$ & 8711.00 (BRL) & 14441.25 (BRL) & 15127.80 & 7256.91 & 47.97 \\
\hline Japan/2015 & 3165203.19 (JPY) & 3275312.27 (JPY) & 41469.90 & 32098.32 & 77.40 \\
\hline $\begin{array}{c}\text { Ontario } \\
(\text { Canada }) / 2016\end{array}$ & $15722.00(\mathrm{CND})$ & $16839.21(\mathrm{CND})$ & 44025.20 & 13259.22 & 30.12 \\
\hline Brazil/2015 & 4559.75 (USD) $^{\star}$ & $18472.94(\mathrm{BRL})$ & 15127.80 & 9282.88 & 61.36 \\
\hline Sweden/2013 & $27710.98(\mathrm{EUR})^{\star}$ & 308476.87 (SEK) & 49174.90 & 34351.54 & 69.86 \\
\hline Italy/2009 & 6536.06 (EUR) & 7177.92 (EUR) & 38160.70 & 9969.33 & 26.12 \\
\hline USA/2008 & 11573.00 (USD) & 15441.89 (USD) & 57466.80 & 15441.89 & 26.87 \\
\hline Poland/2015 & $3408.46(\mathrm{PLN})^{\star}$ & 3755.88 (PLN) & 27810.50 & 2146.22 & 7.72 \\
\hline Mexico/2012 & $91064.00(\mathrm{MXN})$ & $122624.74(\mathrm{MXN})$ & 17861.60 & 14308.60 & 80.11 \\
\hline
\end{tabular}

* Not explicit in the article; data were calculated by the reviewer using data from the article. GDP: Gross Domestic Product; GNI: Gross National Income; PPP: Purchasing Power Parity; USD: United States Dollar (US\$); I\$: International Dollar; EUR: Euro (€); TND: Tunisian Dinar; MAD: Moroccan Dirham; BRL: Real (R\$); JPY: Yen (¥); CND: Canadian Dollar; SEK: Swedish Krona; PLN: Zloty; MXN: Mexican Peso. 


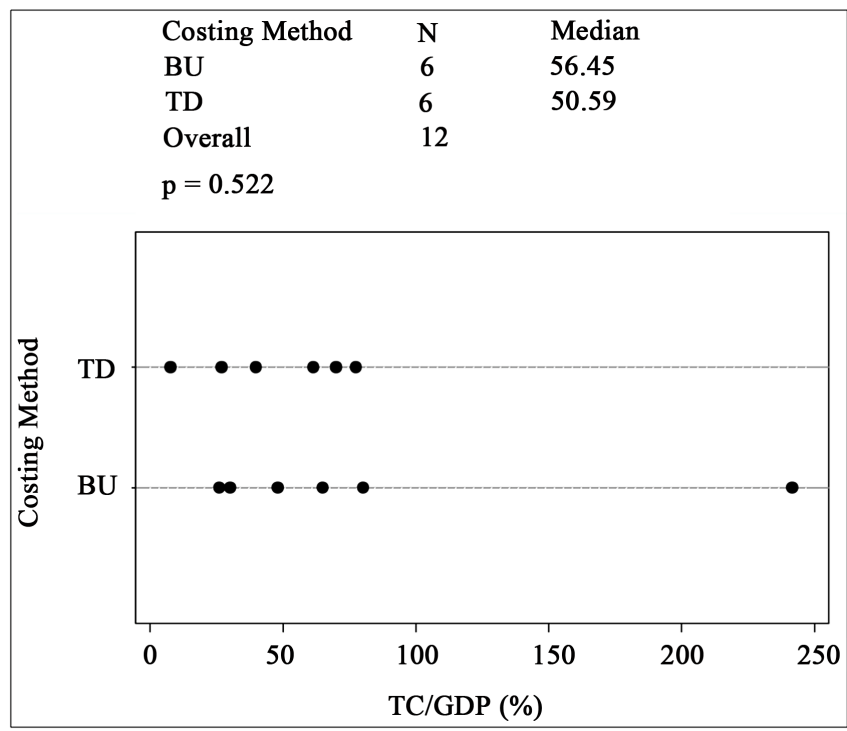

Figure 3. Costs percentage distribution according to costing method. TD: top-down; BU: bottom-up; TC: total ICC treatment costs per patient per year; GDP: gross domestic product per patient.

Although the societal perspective has the stronger claim to be the basis for comparison across studies [33], only one article incorporated the ratio of the mortality cost to the total cost, besides the morbidity cost. The mortality cost was calculated by summing the income that could have been earned in future if death had not occurred; the indirect cost in this article represented $80.5 \%$ of the total costs [27]. Because of this discrepancy, and to make values comparable, we have excluded indirect costs from the statistical analysis.

We found no significant difference in the results derived by different costing methods. Actually, most articles did not name the costing method. However, they did describe how costs were calculated, and could therefore be separated into studies using TD and BU methods. Although BU is the theoretically correct way to estimate service cost, this approach may not be practical in all cases; the resources required for the $\mathrm{BU}$ costing could outweigh the benefit of more accurate costing [11]. Experience shows that the TD approach could be useful and reasonably accurate in cases where marketed health technologies (expensive drugs and medical devices) are responsible for most of the resource costs. In these cases, the BU approach may yield a very similar result, but could be more expensive and time consuming. For international comparative studies, the use of the TD approach is recommended [34].

In this review, MIC had a relatively higher expenditure as percentage of per capita GDP than HIC on the treatment of invasive UCC. This is in some respects different from what was demonstrated in earlier studies, where Latin America spent $7.7 \%$ of its GDP on health, while the USA and Canada spent approximately $18 \%$ and $12 \%$, respectively [4]. This difference can be explained by the lower incidence of invasive UCC in HIC when compared to MIC [1]. Even though HIC had a superior percentage of GDP expenditure on health as a whole, it 
probably was not relevant to invasive UCC.

This study has limitations. First, only four studies specified that the treatment costs were related to the first year after diagnosis. It has been demonstrated that costs may change depending on the time since diagnosis, and costs are the lowest in the period between the initial and end-of-life phase, following a "U-shaped" curve [35]. In fact, costs can be higher when only the cost of the first year of treatment is included, compared to the inclusion of the costs for all phases. In this review, we found two articles referring to Morocco, in which the cost in one study, based on data from the first year of treatment, was more than twice the cost calculated by the other [20] [21]. Second, two articles did not refer to the entire country's population and data were extrapolated [26] [28]. Finally, the lack of clarity in cost concepts and differences in the inclusion and exclusion of cost items made these comparisons problematic. Consequently, the findings should be interpreted carefully.

However, because all costs were adjusted to one common currency and correlated to each country's GDP, we were able to determine the cost of invasive UCC treatment relative to the health budget of each evaluated country. Economic evaluations are important tools to guide decision makers with respect to appropriate resource allocation. The methodology of these studies is heterogeneous, but forms of equivalency should always be sought.

Although we recognize many caveats, this is to our knowledge the only study that has tried to determine a parallel between invasive UCC treatment costs across different regions. The intent is that this would contribute to the continued efforts of policy makers to standardize and develop reproducible economic studies, especially in low and middle-income counties.

\section{Conclusion}

We found that, for the treatment costs of invasive UCC, the percentages of GDP per capita were statistically higher in MIC than in HIC. However, no significant difference was found between costing methods, and the top-down approach could be used.

\section{Conflicts of Interest}

The authors declare no conflicts of interest regarding the publication of this paper.

\section{References}

[1] World Health Organization IA for R on C (2012) Estimated Incidence, Mortality and Prevalence Worldwide in 2012. http://globocan.iarc.fr/Pages/fact_sheets_cancer.aspx

[2] Torre, L.A., Bray, F., Siegel, R.L., Ferlay, J., Lortet-Tieulent, J. and Jemal, A. (2015) Global Cancer Statistics, 2012. CA: A Cancer Journal for Clinicians, 65, 87-108. https://doi.org/10.3322/caac. 21262

[3] Formen D., Ferlay J., Stewart, B.W. and Wild, C.P. (2014) The Global and Regional 
Burden of Cancer. In: Stewart, B.W. and Wild, C.P., Eds., World Cancer Report 2014, IARC, International Agency for Research on Cancer, World Health Organization, Lyon.

[4] Goss, P.E., Lee, B.L., Badovinac-Crnjevic, T., et al. (2013) Planning Cancer Control in Latin America and the Caribbean. Lancet Oncology, 14, 391-436. https://doi.org/10.1016/S1470-2045(13)70048-2

[5] The World Bank (2016) The World Bank in Middle Income Countries. http://www.worldbank.org/en/country/mic/overview

[6] Weinstein, M.C., Siegel, J.E., Gold, M.R., Kamlet, M.S. and Russell, L.B. (1996) Recommendations of the Panel on Cost-Effectiveness in Health and Medicine. Journal of American Medical Association, 276, 1253-1258. https://doi.org/10.1001/jama.1996.03540150055031

[7] Drummond, M.F., Sculpher, M.J., Claxton, K., Stoddart, G.L. and Torrance, G.W. (2015) Methods for the Economic Evaluation of Health Care Programmes. 4th Edition, Oxford University Press, Oxford.

[8] Weinstein, M.C. and Stason, W. (1977) Foundations of Cost-Effectiveness Analysis for Health and Medical Practices. New England Journal of Medicine, 296, 716-721. https://doi.org/10.1056/NEJM197703312961304

[9] Bonis, P.A.L. and Wong, J.B. (2017) A Short Primer on Cost-Effectiveness Analysis. https://www.uptodate.com/contents/a-short-primer-on-cost-effectiveness-analysis

[10] Ministério da Saúde, Secretaria de Ciência, Tecnologia e Insumos Estratégicos and Departamento de Ciência e Tecnologia (2014) Diretrizes metodológicas: Estudos de avaliação econômica de tecnologias em saúde [Methodological Guideline: Economic Evaluaton of Health Technologies]. 2nd Edition, Ministério da Saúde, Brasília, 132 p. http://conitec.gov.br/images/Artigos_Publicacoes/Diretrizes/AVE.pdf

[11] Mogyorosy, Z. and Smith, P. (2005) The Main Methodological Issues in Costing. Health Care Services: A Literature Review. CHE Research Paper 7. Centre for Health Economics, Alcuin College, University of York, York.

https://www.york.ac.uk/media/che/documents/papers/researchpapers/rp7_Method ological_issues_in_costing_health_care_services.pdf

[12] Drummond, M., Barbieri, M., Cook, J., et al. (2009) Transferability of Economic Evaluations across Jurisdictions: ISPOR Good Research Practices Task Force Report. Value Health, 12, 409-418. https://doi.org/10.1111/j.1524-4733.2008.00489.x

[13] World Bank (2016) PPP Conversion Factor, GDP (LCU per International \$). International Comparison Program Database. http://data.worldbank.org/indicator/PA.NUS.PPP

[14] (2017) Historical Inflation Rates: 1914-2017. US Inflation Calculator. http://www.usinflationcalculator.com/inflation/historical-inflation-rates/

[15] The World Bank (2017) Inflation, Consumer Prices (Annual \%). http://data.worldbank.org/indicator/FP.CPI.TOTL.ZG

[16] The World Bank (2017) GDP (Current US\$). http://data.worldbank.org/indicator/NY.GDP.MKTP.CD

[17] The World Bank. GDP per Capita (Current US\$). https://data.worldbank.org/indicator/NY.GDP.PCAP.CD?locations=SL

[18] The World Bank. GDP per Capita, PPP (Current International \$). https://data.worldbank.org/indicator/NY.GDP.PCAP.PP.CD

[19] The World Bank. GNI per Capita, Atlas Method (Current US\$). https://data.worldbank.org/indicator/NY.GNP.PCAP.CD 
[20] Berraho, M., Najdi, A., Mathoulin-Pelissier, S., et al. (2012) Direct Costs of Cervical Cancer Management in Morocco. Asian Pacific Journal of Cancer Prevention: APJCP, 13, 3159-3163. https://doi.org/10.7314/APJCP.2012.13.7.3159

[21] Cheikh, A., Majjaoui, S.E., Ismaili, N., et al. (2016) Evaluation of the Cost of Cervical Cancer at the National Institute of Oncology, Rabat. The Pan African Medical Journal, 23, 209. https://doi.org/10.11604/pamj.2016.23.209.7750

[22] Ricciardi, A., Largeron, N., Giorgi Rossi, P., et al. (2009) Incidence of Invasive Cervical Cancer and Direct Costs Associated with Its Management in Italy. Tumori, 95, 146-152. http://www.ncbi.nlm.nih.gov/pubmed/19579858

[23] Insinga, R.P., Ye, X., Singhal, P.K. and Carides, G.W. (2008) Healthcare Resource Use and Costs Associated with Cervical, Vaginal and Vulvar Cancers in a Large U.S. Health Plan. Gynecology Oncology, 111, 188-196.

https://doi.org/10.1016/j.ygyno.2008.07.032

[24] Annemans, L., Rémy, V., Lamure, E., et al. (2008) Economic Burden Associated with the Management of Cervical Cancer, Cervical Dysplasia and Genital Warts in Belgium. Journal of Medical Economics, 11, 135-150. https://doi.org/10.3111/13696990801961611

[25] Gobrane, H.B., Aounallah-Skhiri, H., Oueslati, F., Frikha, H., Achour, N. and Hsairi, M. (2009) Estimated Cost of Managing Invasive Cervical Cancer in Tunisia. Santé Publique, 21, 561-569. http://www.cairn.info/revue-sante-publique-2009-6-page-561.htm

[26] Fonseca, A.J., Ferreira, L.P., Dalla-Benetta, A.C., Roldan, C.N. and Ferreira, M.L.S. (2010) Epidemiology and Economic Impact of Cervical Cancer in Roraima, a Northern State of Brazil: The Public Health System Perspective. Revista Brasileira de Ginecologia e Obstetricia, 32, 386-392. https://doi.org/10.1590/S0100-72032010000800005

[27] Hayata, E., Seto, K., Haga, K., Kitazawa, T., Matsumoto, K. and Morita, M. (2015) Cost of Illness of the Cervical Cancer of the Uterus in Japan-A Time Trend and Future Projections. BMC Health Service Research, 15, 1-9. https://doi.org/10.1186/s12913-015-0776-5

[28] Liu, N., Mittmann, N., Coyte, P.C., Hancock-Howard, R., Seung, S.J. and Earle, C.C. (2016) Phase-Specific Healthcare Costs of Cervical Cancer: Estimates from a Population-Based Study. American Journal of Obstetrics and Gynecology, 214, 615.e1-615.e11. https://doi.org/10.1016/j.ajog.2015.11.021

[29] Novaes, H.M.D., Itria, A., Silva, G.A., et al. (2015) Annual National Direct and Indirect Cost Estimates of the Prevention and Treatment of Cervical Cancer in Brazil. Clinics, 70, 289-295. https://doi.org/10.6061/clinics/2015(04)12

[30] Östensson, E., Fröberg, M., Leval, A., et al. (2015) Cost of Preventing, Managing, and Treating Human Papillomavirus (HPV)-Related Diseases in Sweden before the Introduction of Quadrivalent HPV Vaccination. PLOS ONE, 10, 1-15. https://doi.org/10.1371/journal.pone.0139062

[31] Holecki, T., Sobczyk, K., Nawrocki, S., Woźniak-Holecka, J., Skrzypek, M. and Bocionek, A. (2015) Costs of Malignant Cervical Cancer Curing in Poland in the Years 2011-2012 the Case of the Silesian Voivodeship. Polish Gynaecology, 86, 849-855.

[32] Sánchez-Román, F.R., Carlos-Rivera, F.J., Guzmán-Caniupan, J.A., Escudero-De Los Ríos, P., Juárez-Pérez, C.A. and Aguilar-Madrid, G. (2012) Health Care Costs for Cervical Cancer. Revista Médica del Instituto Mexicano del Seguro Social, 50, 99-106. https://www.redalyc.org/articulo.oa?id=4577455493019

[33] Russell, L.B., Gold, M.R., Siegel, J.E., Daniels, N. and Weinstein, M.C. (1996) The 
Role of Cost-Effectiveness Analysis in Health and Medicine. Panel on Cost-Effectiveness in Health and Medicine. Journal of American Medical Association, 276, 1172-1177. https://doi.org/10.1001/jama.1996.03540140060028

[34] Negrini, D., Kettle, A., Sheppard, L., Mills, G.H. and Edbrooke, D.L. (2004) The Cost of a Hospital Ward in Europe: Is There a Methodology Available to Accurately Measure the Costs? Journal of Health Organization and Management, 18, 195-206.

[35] Yabroff, K.R., Lund, J., Kepka, D. and Mariotto, A. (2011) Economic Burden of Cancer in the United States: Estimates, Projections, and Future Research. Cancer Epidemiology, Biomarkers \& Prevention, 20, 2006-2014.

https://doi.org/10.1158/1055-9965.EPI-11-0650 